\title{
Article \\ Never in Our Imaginations: The Public Human Resources Response to COVID-19 in Northwest Florida
}

\author{
Christopher L. Atkinson 1,2 (D) \\ 1 Department of Administration and Law, University of West Florida, Pensacola, FL 32514, USA; \\ catkinson1@uwf.edu \\ 2 School of Public Policy and Administration, Walden University, Minneapolis, MN 55401, USA
}

Citation: Atkinson, C.L. Never in Our Imaginations: The Public

Human Resources Response to COVID-19 in Northwest Florida. COVID 2022, 2, 102-116. https: / / doi.org/10.3390/covid2020008

Academic Editor: Andrea Fiorillo

Received: 22 December 2021

Accepted: 17 January 2022

Published: 19 January 2022

Publisher's Note: MDPI stays neutral with regard to jurisdictional claims in published maps and institutional affiliations.

Copyright: (C) 2022 by the author. Licensee MDPI, Basel, Switzerland. This article is an open access article distributed under the terms and conditions of the Creative Commons Attribution (CC BY) license (https:// creativecommons.org/licenses/by/ $4.0 /)$.

\begin{abstract}
The Coronavirus disease 2019 (COVID-19) pandemic has placed unprecedented demands on the whole of society. The public sector human resources (HR) function has played a key role in responding to COVID-19. This paper considers: How did public sector HR organizations in Northwest Florida respond during the COVID-19 pandemic? What are lessons learned from the perspectives of resilience and vulnerability? Interviews were conducted with HR professionals in Northwest Florida in early 2021. Responses suggested many points that show resilience, sensemaking, and adaptive capacity. However, some aspects of responses indicate the presence of vulnerability, as well as concerns with leadership and management.
\end{abstract}

Keywords: human resources; COVID-19; Northwest Florida; resilience; vulnerability; adaptive capacity

\section{Introduction}

"None of us ever anticipated a pandemic that would last for a year, with people working at home. We are accustomed to hurricanes and floods and tornadoes, and things that take people out of commission for, you know, weeks or months. We have reacted, I think, appropriately in the past by filling gaps where we needed to wear offices when we're not able to be occupied, or people's internet wasn't available, so we had to equip them so that they could work at home or in a temporary office, but never in our imaginations did we conjure up the necessity for a staff of . . 700 plus people to be working at home ... I wish our vision had been broader" - an HR professional in Northwest Florida

The Coronavirus disease 2019 (COVID-19) pandemic has placed unprecedented demands on the whole of society, from individuals to business and governments. The changes in response were often massive, with few interests escaping impact [1]; where recovery has occurred, it has unfolded slowly amid the continuing effect of the disease globally. COVID-19 has created havoc with standard processes, and disrupted the infrastructure of modern life. Delays and closures have negatively impacted the ability of government and nonprofit organizations to do the public's work.

The implications of the response to COVID-19 in public sector organizations are farreaching. Organizations have had to make sense of a changing, challenging context, make adjustments to usual ways of doing business, and still function well enough to accomplish public goals. The COVID-19 response has illustrated the ingenuity of public sector officials, and provided examples of problem solving under significant duress, but a lack of optimal response and failure more broadly in other aspects has called into question the general resilience, if not sustainability, of public enterprises.

The public sector human resources (HR) function plays a key role in any response to crisis - this has been the case in responding to COVID-19. Tagarev and Ratchev observed that the heightened risk from disaster events necessitates increased focus on interdependent capabilities within crisis management functions, of which human resources is an important facet [2]. HR is central to the ability of government to respond acceptably and as expected. 
Even with the pandemic continuing across the world, much has been published of value in the academic literature on how organizations have responded. Less has been published on how public sector human resource functions, within governments and nonprofit organizations, have responded to the pandemic and the various challenges associated with serving organizational missions, addressing personnel needs, and responding to the changed context and additional requirements brought about by COVID-19.

This paper considers: How did public sector HR organizations in Northwest Florida respond during the COVID-19 pandemic? What are lessons learned from the perspectives of resilience and vulnerability? First, literature is considered on resilience, vulnerability, and the HR function during COVID-19. Materials and methods for the study follow, along with analysis, discussion, and a concluding statement. HR agencies and representatives in Northwest Florida were tasked with a momentous responsibility during the COVID-19 pandemic; HR professionals' responses in interviews suggested many points that show resilience, sensemaking, and adaptive capacity. However, some aspects of their responses indicate the presence of vulnerability, as well as concerns with leadership and management, including inconsistency in official direction that at times hampered efforts to be fully responsive to the crisis.

\section{Literature Review}

\subsection{Resilience and Vulnerability}

This section briefly discusses concepts of resilience, vulnerability, and related concepts of adaptive capacity and sensemaking. While a full treatment of these concepts is beyond the scope of this paper, numerous works on these topics exist in the literature [3-11].

Resilience has been an increasingly common term in practice as individuals and organizations seek to respond effectively to the changing, complex world around them. While the term is commonly used, there is disagreement on how it is defined. Ecologist C. S. Holling described resilience as "a measure of the persistence of systems and of their ability to absorb change and disturbance and still maintain the same relationships between populations or state variables" [12]. Later, W. Neil Adger described resilience as "the magnitude of disturbance that can be absorbed before a system changes to a radically different state as well as the capacity to self-organise and the capacity for adaptation to emerging circumstances" [13].

Resilience focuses on ways of transforming and adapting in response to changing circumstances and particularly crises (crises being "low probability/high consequence events that threaten the most fundamental goals of an organization") [14]. This involves not only how individuals, groups, and institutions respond in the short-run, but also how they adapt to the circumstances, and maintain or even grow more successful despite the challenges faced. Individuals and their groups can learn from one another, improving their responses and ability to serve clients and customers, or in the case of government and nonprofit organizations, citizens. Individuals that are more connected with others might be seen as more resilient [15]. It is not enough for society, institutions, and individuals to simply return to normal, especially if the previous normal represented an unjust system with weakness in critical areas. Resilience is not simply a matter of within-organization practice and management; the larger context within which an organization operates plays a role in the resilience that an organization may achieve [16]. From the perspective of experiences with COVID-19, Carnevale and Hatak noted the importance of being "forward thinking" in an era of unprecedented challenges [17], and this is consistent with resilience principles.

Resilience and vulnerability are related concepts. As with resilience, vulnerability is considered an important factor, but consensus on definition might be described as elusive. Vulnerability has been defined as the "degree to which a system is susceptible to and is unable to cope with adverse effects," with key components in "the stress to which a system is exposed, its sensitivity, and its adaptive capacity" [13].

Vulnerability study considers ways that society-its members and institutions of all sorts-are exposed, possibly more than others, to hazards, in ways that might potentially 
limit the ability for organizations and processes to 'bounce back' and recover from a hazard. An inability to recover from a hazard event may turn a relative inconvenience into a disaster, so addressing vulnerability is an essential aspect of strengthening that can occur before hazard events. Vulnerability includes not only the point of threat, but also a potential lack of ability to cope with a potential threat. Serious problems and inconsistencies that existed before a crisis event persist into the post-crisis environment, potentially becoming magnified as a result of stress on individuals and groups. Failures to plan and save resources to mount an effective response can become evident. Organizations are becoming more aware of the broad range of risks that exist and represent threats, and possible opportunities to plan and enhance resilience. For example, in 2004 the United Nations issued a report on threats and risk; the report included comments not only on natural threats, but terrorism, and, presciently, the potential for global pandemic, given historical instances [18].

Overconfidence itself can be a point of vulnerability. Individually, low self-esteem can be a source of vulnerability [15]. There can be a rush to 'return to normal', with decisions being made that have less to do with the crisis faced, and more to do with policy and process tools already available, and a need to move on from the event [8], perhaps prematurely. Vulnerabilities can also be tied to emotional aspects of responding to crisis, and the ability to respond to challenges on an individual basis [19]. This can ultimately inform how an organization responds, through capable management and direction, or explain shortfalls in this area.

The tendency to show resilience regularly involves displays of adaptive capacity, which has been defined by as "the potential or ability of a system, region, or community to adapt to ... effects or impacts ... Enhancement of adaptive capacity represents a practical means of coping with changes and uncertainties ... including variability and extremes ... enhancement of adaptive capacity reduces vulnerabilities" [20]. Adaptation plays a role in human resources management in terms of adjusting competencies over time [21]. From a public sector perspective, though, adaptive capacity can be reduced in intensely political environments [22].

As a further illustration of interaction and possible enhancement during response to a hazard or crisis, the ability of individuals and groups to make sense of their circumstances and more effectively solve problems can also be a critical aspect of returning to normalcy. Sensemaking suggests that "reality is an ongoing accomplishment that emerges from efforts to create order and make retrospective sense of what occurs" [23]. Sensemaking was described by Sparrow as "emotionally-tinged cognition" in an environment of complexity and ambiguity [21]. Weick suggested that sensemaking could be a source of resilience, through "improvisation, virtual role systems, the attitude of wisdom, and norms of respectful interaction" [23]. Stephens and colleagues made use of sensemaking in the context of COVID-19, where they recommended a closer relationship between scholars and communities to make practical, meaningful change [24].

Not all shocks to a system cause the same level of crisis or need for realignment; some crises rise to a level of severity, termed ontological crisis, that affect people at the level of identity, and this may ultimately affect sensemaking processes [25]. Belli and Alonso identified that people may influence one another emotionally, and that emotional contagion can lead people to respond positively to challenges, or to seeking out information sources that reinforce what they believe to be true, even if the viewpoint is invalid. Ability to comprehend and trust, as well as perception of grief and even time, have potentially been altered by the pandemic, leading to decision-making and interpersonal interaction that is strained or ineffective [26].

\subsection{The Human Resources Function during COVID-19}

Human resources development has been defined by McLagan and Suhadolnik as "integrated use of training and development, career paths, and organizational development to improve individual and organizational effectiveness" [27]. HR has an essential role in serving organizations and helping them to accomplish their goals through staffing, but also 
in protecting employees, leading to resilient organizations; more calculating aspects like risk assessment are balanced with empathy and an awareness of the value of inclusion [28] The aspects of protecting employees and providing for continuity in organizations came to the fore during the COVID-19 response; normal processes and approaches were often inadequate, or in need of considerable revision, in order to allow organizations to continue during the pandemic, even in reduced capacity.

From an HR perspective, normal processes have likely been impacted in a variety of organizations by COVID-19, regardless of organization; these might include onboarding, attracting candidates, compliance issues, maintaining engagement and organizational commitment, issues with benefits packages, and how flexible environments have impacted management's ability to work with available talents [29].

The human resources function is central to the enabling of innovative capacity within public sector organizations [10]. The HR function has been connected to innovation in the literature, and is increasingly a matter of strategic importance as organizations are called to respond with flexibility to a changing environment [30]. Within the COVID-19 pandemic, concerns about the need for human resources scenario planning were raised. Without scenario planning exercises included as part of an ongoing active planning program, it can be difficult for organizations to know how processes and people will respond to extreme events, or grow potential for resilient responses [31].

In the literature on the control of pandemics and human/organizational factors, $\mathrm{Fu}$ et al. identified qualitative work focusing on "understaffing, lack of medical and emergency supplies, lack of emergency drills, improper safety protection operation, improper administration of epidemic areas, improper surveillance of imported cases of infection, concealed report on or release of epidemic information, poor technical ability ... insufficient public intervention, and imperfect management and response mechanisms for emergencies" [32]. Many of these previous studies focus on aspects related generally to human resources, either on personal readiness to respond to issues, or supervision-related problems [32].

Jones observed that it is the role of HR to protect employees so that they can safely engage in their work [33]. Keeping workplaces sanitary is essential during a pandemic. Adjustments may have to be made in how employees are tracked and evaluated when they are working remotely. Over-reaction or under-reaction by employers can create serious problems with organizational liability, in reducing staffing too much, or engaging in discriminatory behavior under the guise of pandemic response [33].

In the context of COVID-19, nonprofit employees raised concerns about loss of voice within organizations, felt a sense of disempowerment and high levels of stress, and had concerns about information not being shared with them about decisions affecting the organization [34]. There have been calls within the pandemic response to balance public health needs with economic and workplace needs, along with cautions to document the pandemic as the rationale when terminating employees [35].

\subsection{Telework}

In responding to COVID-19, governments often turned to working-from-home or telework arrangements, to allow official functions to proceed [36] while seeking to minimize disease spread and health risk to staff and the public. Telework has been used to respond to the extraordinary nature of the COVID-19 pandemic, including calls for 'lock-down' type quarantines in place, but there has been some recognition that telework also provides the opportunity to accomplish needed tasks with only small adaptations necessary, at potential savings in infrastructure cost [37]. Telework may "help to motivate the members of the organization ... balance work and private life, maintain health and productivity, flexibly plan working hours, experience less stress related to communication, work without being constantly controlled by managers, and save time travelling to and from the workplace," but it could present challenges for socialization, work/life balance, or communication with management and team members [38]. Availability of remote working arrangements in 
service to public health has revealed serious concerns about societal inequality in some cases [39].

Interest in work-from-home arrangements is constrained by "unsupportive work cultures and attitudes, particularly managerial concerns about trust, productivity, and underperformance... [as well as] inadequate technology and concerns about [policy] compliance" [40]. Nevertheless, necessity may clear outmoded or unsupported attitudes when reality dictates; concerns, especially those that speak to distrust of employees, perhaps say as much about managerial quality as employee commitment and productivity. While it remains to be seen whether working-from-home will continue beyond the pandemic, having the plan to use such approaches in place likely increases organizational capacity [40], even with concerns about how it may negatively impact work-life balance [36].

Beyond teleworking, COVID-19 demonstrated that digitalization of other processes was essential to keep processing moving forward, as many traditional processes failed due to the constraints of the pandemic and failing to use technological tools effectively [41].

\subsection{Planning and Preparedness}

Having plans is important to disaster preparedness, but given the nature of people in complex or challenging circumstances, it is not reasonable to assume that matters will always go according to plan. People respond given their motivations and backgrounds; disruptions do not always have to yield crisis, as they can lead to innovation, but this tends to require an entrepreneurial mindset [42]. Within public organizations, determining priorities and the outlay of resources, including human resources, is a subjective matter. Trade-offs are shaped [43] and it is worth knowing how prioritization decisions are made in context of crisis situations, such as COVID-19.

Awareness of and ability to respond to vulnerability is an essential part of disaster preparedness. Vulnerability in a community may present significant constraints on government activities, necessitating heightened collaboration with the private sector or across governmental agencies [44]. Vnoučková noted how important it is for organizations to be prepared, to provide for an improved response to events [45]. Medel, Kousar, and Masood suggested that public organizations working with private sector concerns may yield improved disaster management response; relief goods and services cannot be expected from systems that are not resilient. Quickness, robustness, flexibility, and agility are desirable elements of collaboration [46]. However, Mellish, Luzmore, and Shahbaz suggested that preparedness to respond to pandemics has been undermined by inadequate resources, deregulation, and privatization associated with larger trends toward neoliberalism [47].

\subsection{Changing Thinking on High Reliability Organizations and 'High Probability' Shocks}

Amankwah-Amoah, Khan, and Wood wrote that novel shocks like COVID-19, climate change, and political instability may actually be considered high probability. They suggested that "none of these developments are novel ... there have been innumerable attempts to raise awareness about their high probability and the risks they bring with them ... their occurrence transcends the past body of recent experience ... dealing with them will require fundamental economic, political, and environmental changes" [48]. As so much of public enterprise relies on human resources operations to function well or at all, it could be said that HR functions constitute 'high reliability organizations' [49]. When 'high reliability organizations', such as HR as an essential internal service agency, function well in a crisis, the potential for enhanced trust and value among customers, internal and external (citizens) is increased.

Figure 1 shows a conceptual framework for public sector HR response during COVID-19. Influencing the decisions and actions of public sector HR agencies are internal pressures, including political pressures, employee needs, the needs of fellow agencies within the entity [50]. Norms and culture within the organization may have an impact. External pressures encompass intragovernmental pressures, political inclinations of full reopening of operations and the economy generally, and larger management/organizational leadership 
considerations. Professional practice includes HR norms of service, professionalism, and ethical responsibility. An influencing factor that has played special importance during the COVID-19 response was the role of official guidance, including direction from the Centers for Disease Control (CDC), among other sources. Even if local and state officials make decisions for response, responding in the fog of war of COVID-19 often challenged officials to respond with incomplete or incorrect understanding, making the role of CDC in providing clear, actionable information that much more important. As this information and direction had a tendency to be changeable at various points in the response, this may have influenced $\mathrm{HR}$ responses in both positive and negative ways. The surrounding environment is characterized by the disease itself, COVID-19, impacting the other influencing factors and the HR organization directly.

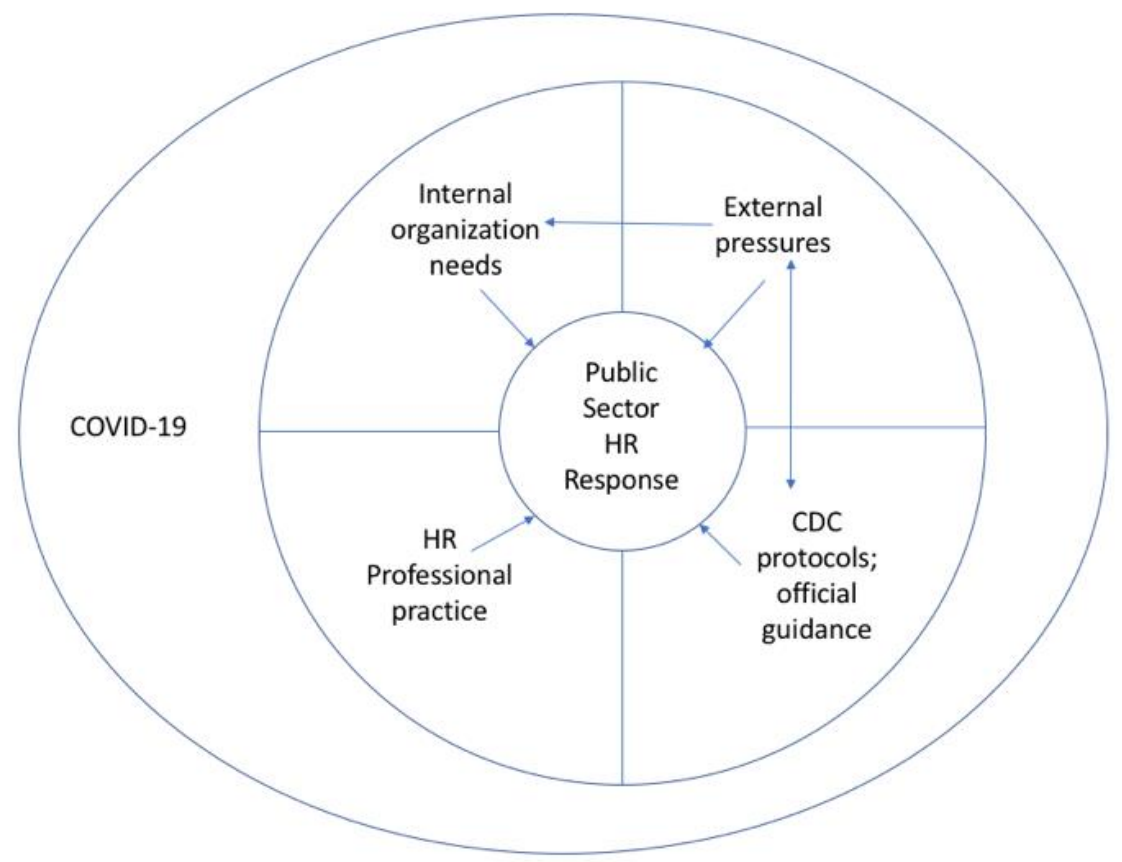

Figure 1. Describing wheel framework: Influences on public sector HR during COVID-19.

\section{Materials and Methods}

The frame for this study is public sector human resources agencies (in government and nonprofit organizations) in Northwest Florida. The selection of this area helped narrow the respondent pool and allow focus on this particular region (which is served by the regional university where the author is employed) and its response to COVID-19, as a respondent frame. A goal was to provide for potentially contrasting cases, including large and small organizations, public sector agencies in both government and nonprofit sectors, and organizations with different missions and goals, to encourage more robust understanding of phenomena encountered through contrasts, as well as to improve generalizability. Another consideration was to provide for a representative sample of HR experiences in this regional frame, but also to identify any particularly negative or exceptional responses [51]. The interviews with HR professionals, having some role in supervision or being responsible for agency recruitments, took place from February 16 through 22, 2021, as part of a graduate level human resources management course in a public administration program at the University of West Florida, Pensacola, FL, USA. A range of organizations, including state and local government, and nonprofit organizations, were represented among those interviewed.

The project was reviewed by the IRB at University of West Florida, IRB no. 2020055 , and each interviewee signed an informed consent form for participation. Interviews were conducted by students as part of this larger IRB-reviewed and approved project; the 
university encourages student-involved research, but beyond this, interviewing skills are valuable in the course of human resources practice, so the project served a variety of goals. Interviewing skills are extensively utilized and refined in the course, and the finer points of research-related interviewing were included as part of the course offering [52]. Studentinvolved research allows for development of critical thinking, and can help students understand practice, and influence the approaches they use later in their careers [53].

Each interview was conducted using a semi-structured questionnaire with six questions (see Box 1). Students were directed to consider the types of organizational learning that may have occurred during the pandemic, and to encourage the sharing of insight about what worked in responding to the crisis, when developing potential questions. The students in the course developed the questions with guidance from the instructor, and then voted on them as a class through a Qualtrics survey; students had a choice of 29 potential questions, and the top six questions were selected. Each student was allotted 100 points to vote on various question options, so that they could decide which questions they thought were best, and how much they supported their choices. The cumulative scores from the class for each interview question resulted in selection of questions that showed interest in the COVID-19 pandemic response from resilience perspectives and in learning about how the pandemic impacted HR activities, to inform future responses.

Box 1. Semi-structured interview questions, Human resources responses to COVID-19. Connection to research question/literature in italics.

1. If you could learn from mistakes made in adapting to COVID-19, what steps, policies, or procedures would you have implemented earlier? (Adaptive capacity—resilience)

2. How did your organization resolve differences between employees who had to physically report to work and those that were authorized to work from home? (Vulnerability)

3. Has there been any discussion within your agency about; permanent changes stemming from the pandemic with regard to teleworking and maintenance of office space? (Resilienceinnovation)

4. How has your organization been handling telework, on-boarding, and (to the extent you have had any) layoffs during the pandemic? Has this affected employee engagement? (Resilienceadaptive capacity - changes approaches to support organization continuity)

5. How has employee productivity been impacted by COVID? (Resilience)

6. Has your agency altered the hiring, on boarding, and initial training process for new staff members due to the teleworking situation? If so, what are the pros and cons of the new process versus the previous process prior to COVID? (Resilience-adaptive capacity-changes approaches to support organization continuity)

A desire for consistency in approach to interviewing figured in discussions about using a semi-structured interview format. While all students used the same interview questionnaire, it was understood that respondents might answer them differently, and want to spend more time talking about certain aspects; as the approach intended to understand the response from the perspective of those working through it, students were encouraged to let respondents tell their stories and spend more time when necessary on certain aspects they deemed important. This noted, the semi-structured interviews allowed for some consistency, without sacrificing the potential for understanding contexts and the rich detail of experience offered by respondents [51]. Each question is adequately rooted in the literature, as responses may confirm or oppugn previous understanding about resilience and vulnerability.

Each student had the option of interviewing a respondent on their own or with a fellow classmate. Interview results were submitted mostly as audio recordings, with a few cases being submitted as transcribed text, or detailed notes. The resulting sample included 27 interviews with a variety of public sector human resources representatives. The collected interviews were transcribed where needed (some were submitted already transcribed or as detailed notes), anonymized, and collected into a corpus for analysis. 


\section{Analysis}

As noted above, the research questions for this project were: How did public sector HR organizations in Northwest Florida respond during the COVID-19 pandemic? What are lessons learned from the perspectives of resilience and vulnerability?

Generally speaking, this analysis follows Miles, Huberman, and Saldaña's flows of analytical activity: data condensation, data display, and drawing and verifying conclusions. Condensing data, from interviews for example, makes the data stronger by emphasizing themes that exist across a slate of interviews. Analytic choices about coding and which themes are important are interpretive-finding connections between sub-topics that relate to larger themes. In this case, the interview questions and resulting responses lend themselves to existing literature not only on the HR function and the role of management in responding to crisis, but on resilience and vulnerability in organizations [51].

MAXQDA was utilized for the computer-aided qualitative analysis. Interview text files were imported into the software for analysis. The resulting corpus was analyzed in an open fashion, to allow for the development of ideas that could be connected to existing theory, without predispositions toward certain outcomes, such as levels of resilience or vulnerability seen in certain respondent organizations. First cycle coding thus involved initial coding, which "breaks down qualitative data into discrete parts, closely examines them, and compares them for similarities and differences" [52]. In the course of open coding, there was a recognition that responses lent themselves to a resilience/vulnerability theoretical approach. Theoretical coding [52] was thus employed to identify central concerns and the main theme of the corpus as a whole. Codes from the first cycle were organized, as expected given the grounding in literature, around the major themes of vulnerability and resilience, with some comments amounting to lessons learned for management and leadership. Subtopics allowed for more granular understanding of how those concepts were encountered and understood in practice by respondents. The use of only a few major category themes simplified the analysis and made the coding decisions from first cycle to second more direct [54].

The results of the analysis are included in Table 1 as a code frequency table [51]. Major themes included resilience, vulnerability, and leadership/management considerations, and account for $89.2 \%$ of all codes (447 coded segments), and sub-themes are arranged in support of main themes. Qualitative textual analysis is somewhat subjective; however, the themes encountered in the analysis, based upon interview responses, have clear connection to the literature on organizational resilience (triangulation to and congruency with existing theory) [51]. Some aspects, such as the importance of telework, have been noted as very important in COVID-19 response in the literature review, and this emphasis also exists in the corpus of interviews for this project. None of the responses were particularly extreme, in a way that would cause concern about their inclusion in the analysis; no bias or deceit was noted or expected [51]. While no deception was sensed in analysis of the interviews, and no reason to question the candor of respondents was evident, it is worth noting that this study rests on the perspectives of the people involved in the response, and the intent is to tell their collective story, rather than to validate or refute any particular perspective. The author has previously written and published on the topic of resilience, and has a prolonged engagement with such study in this field [55]. 
Table 1. Code Frequency Table, Analysis of Interview Corpus, NW Florida Public Sector HR Interviews (Major themes in bold; major code categories in italics).

\begin{tabular}{|c|c|c|c|}
\hline RESILIENCE & Coded Segments & $\%$ of Theory Theme & $\%$ of All Coded Segments \\
\hline $\begin{array}{c}\text { Sensemaking/brainstorming/adaptive } \\
\text { capacity/teamwork }\end{array}$ & 45 & $19.0 \%$ & $9.0 \%$ \\
\hline $\begin{array}{l}\text { Technology/infrastructure enhancements, incl. } \\
\text { zoom meetings/Microsoft Teams }\end{array}$ & 24 & $10.1 \%$ & $4.8 \%$ \\
\hline Remote work/telework & 24 & $10.1 \%$ & $4.8 \%$ \\
\hline Productivity maintained or improved & 26 & $11.0 \%$ & $5.2 \%$ \\
\hline Virtual onboarding & 19 & $8.0 \%$ & $3.8 \%$ \\
\hline Employee engagement high & 12 & $5.1 \%$ & $2.4 \%$ \\
\hline Work the same, just virtual & 19 & $8.0 \%$ & $3.8 \%$ \\
\hline Work/Life balance & 2 & $0.8 \%$ & $0.4 \%$ \\
\hline Employment maintained & 20 & $8.4 \%$ & $4.0 \%$ \\
\hline $\begin{array}{l}\text { Potential of long-term permanent } \\
\text { changes/options }\end{array}$ & 20 & $8.4 \%$ & $4.0 \%$ \\
\hline Subtotal-Resilience group & 211 & $89.0 \%$ & $42.1 \%$ \\
\hline \multicolumn{4}{|l|}{ VULNERABILITY } \\
\hline Delays and failures & & & \\
\hline Telework/distances drawbacks & 17 & $10.4 \%$ & $3.4 \%$ \\
\hline $\begin{array}{c}\text { Personal protective equipment (PPE) should } \\
\text { have been mandated earlier }\end{array}$ & 3 & $1.8 \%$ & $0.6 \%$ \\
\hline Technology/infrastructure needed & 18 & $11.0 \%$ & $3.6 \%$ \\
\hline Slow start in response/delays & 9 & $5.5 \%$ & $1.8 \%$ \\
\hline Emotional aspects not well-addressed & & $0.0 \%$ & \\
\hline $\begin{array}{c}\text { Employee engagement limited or not well } \\
\text { understood }\end{array}$ & 15 & $9.2 \%$ & $3.0 \%$ \\
\hline Productivity decreased & 10 & $6.1 \%$ & $2.0 \%$ \\
\hline Sick leave use and abuse/absenteeism & 2 & $1.2 \%$ & $0.4 \%$ \\
\hline Policies unclear or lacking & & $0.0 \%$ & \\
\hline Policy for telework & 13 & $8.0 \%$ & $2.6 \%$ \\
\hline Needed more detailed policies & 4 & $2.5 \%$ & $0.8 \%$ \\
\hline Needed accurate job descriptions & 2 & $1.2 \%$ & $0.4 \%$ \\
\hline Over-confidence & 1 & $0.6 \%$ & $0.2 \%$ \\
\hline We responded well/did a great job & 12 & $7.4 \%$ & $2.4 \%$ \\
\hline $\begin{array}{c}\text { Asking wrong questions/not acknowledging } \\
\text { uncertainty }\end{array}$ & 4 & $2.5 \%$ & $0.8 \%$ \\
\hline $\begin{array}{c}\text { Assuming impacts from disease would be } \\
\text { brief/minimal }\end{array}$ & 2 & $1.2 \%$ & $0.4 \%$ \\
\hline $\begin{array}{l}\text { Systemic vulnerability (including additional } \\
\text { expense, manual processes, and reliance on } \\
\text { young people/trainees) }\end{array}$ & 4 & $2.5 \%$ & $0.8 \%$ \\
\hline Outdated or presumptive views & & $0.0 \%$ & \\
\hline Changes are COVID-only & 7 & $4.3 \%$ & $1.4 \%$ \\
\hline Initial suspicion of remote work & 2 & $1.2 \%$ & $0.4 \%$ \\
\hline Pointedly stating remote work will not continue & 1 & $0.6 \%$ & $0.2 \%$ \\
\hline Responses to disease inappropriate & & $0.0 \%$ & \\
\hline COVID still rampant, employees still sick & 2 & $1.2 \%$ & $0.4 \%$ \\
\hline $\begin{array}{c}\text { Office protocols/responding to changing CDC } \\
\text { requirements (negative) }\end{array}$ & 17 & $10.4 \%$ & $3.4 \%$ \\
\hline Subtotal-Vulnerability group & 145 & $89.0 \%$ & $28.9 \%$ \\
\hline LEADERSHIP/MANAGEMENT/SUPERVISION & & & $0.0 \%$ \\
\hline Leadership/communication important & 9 & $8.9 \%$ & $1.8 \%$ \\
\hline Training & 14 & $13.9 \%$ & $2.8 \%$ \\
\hline $\begin{array}{l}\text { Lack of clarity in direction/CDC had adverse } \\
\text { impact on response }\end{array}$ & 1 & $1.0 \%$ & $0.2 \%$ \\
\hline Information flow to employees & 3 & $3.0 \%$ & $0.6 \%$ \\
\hline Changed work environment & 12 & $11.9 \%$ & $2.4 \%$ \\
\hline Partial return to work & 2 & $2.0 \%$ & $0.4 \%$ \\
\hline Flexible arrangements based on employee needs & 11 & $10.9 \%$ & $2.2 \%$ \\
\hline
\end{tabular}


Table 1. Cont.

\begin{tabular}{cccc}
\hline RESILIENCE & Coded Segments & \% of Theory Theme & \% of All Coded Segments \\
\hline Return to office/telework ended & 5 & $5.0 \%$ & $1.0 \%$ \\
Essential workers & 6 & $5.9 \%$ & $1.2 \%$ \\
Employees unhappy returning to office & 5 & $5.0 \%$ & $1.0 \%$ \\
Some employees not allowed to work & 5 & $5.0 \%$ & $1.0 \%$ \\
remotely/job function & & $2.0 \%$ & $0.4 \%$ \\
Long-term impacts of COVID on workforce & 2 & $11.9 \%$ & $2.4 \%$ \\
planning & 12 & $2.0 \%$ & $0.4 \%$ \\
Office space & 2 & $2.0 \%$ & $0.4 \%$ \\
Negative repercussions of poor leadership & 2 & $90.1 \%$ & $18.2 \%$ \\
Lack of foresight/imagination & 91 & & $89.2 \%$ \\
Subtotal-Leadership group & 447 & &
\end{tabular}

The above caveats noted, the study's data, including the MAXQDA analysis file, are available upon request to the author, for the sake of transparency.

\section{Discussion}

The presence of vulnerability prior to the impacts of COVID-19 likely did have a negative impact on responses, limiting resilience and the potential for systems to adapt and for organizations to achieve their goals. Organizations that exhibited resilient behaviors were more able to adapt to changing circumstances, and this was often represented in thoughtful, considered responses from officials representing these agencies. HR professionals in the sample seemed astute and honest about the response to COVID-19. These professionals responded that issues resulting from COVID-19 were often crushing, but as professionals they were focused on service quality and organizational mission, to serve clients and stakeholders (internal and external). Some public sector HR organizations in Northwest Florida responded during the COVID-19 in ways that showed resilience in the face of challenge, but some others allowed vulnerabilities to limit the potential positive benefit of responses. The tendency toward slow decision making, errant pre-pandemic approaches, and denial of the threat and severity of COVID-19, were all notable. A discussion of the major thematic areas derived from the analysis of interviews, as noted above in Table 1, follows. This discussion is structured around the major themes, with subthemes providing additional detail that either confirms or challenges existing understanding about HR responses during COVID-19.

\subsection{Resilience}

As may be expected, with a shift to virtual work in many cases in the public sector, many comments tended toward technological infrastructure requirements, the provision of which allowed organizations to return to productivity, some with considerable success. The analysis suggests that a major effort was in provisioning the means to work-from-home, often to a large employment base. To this end, much of the conversation from a resilience standpoint addressed adaptive capacity and sensemaking; HR professionals were not only part of the team for problem-solving in public organizations-they often served a leadership role in such efforts. One official indicated that "There's been a tremendous amount of creativity that's come out of [the] team as well. So we're managing, and ... there's been good and bad. That's come from this learning. And we're grateful. And I think we'll be better for it. When it's all said and done." Problem solving and working together with team members was a central theme, which indicates resilient tendencies.

A point for resilience is the use of remote work/telework during the pandemic. Many respondents indicated that productivity levels went up, with some noting that there was improved work/life balance, as well as enhanced understanding (and a sense of appreciation) between employee and employer. The mission of organizations, in many cases, became 
the central consideration, and employees and organizations recommitted themselves to public service. While telework was an important aspect of work during the past year for the HR professionals interviewed, an aspect of response variation among organizations is the shift to virtual work and electronic processing. Some organizations have embraced this and plan to continue to make use of the changes, and benefits realized, as they move back to ways of working that are more like what had previously been considered normal. Others utilized electronic processing of documents and virtual interviews, but seem to have little interest in continuing any of these changes in the post-COVID environment. School districts, particularly, were noted as making temporary changes, seeing their work as in-person for both delivery of services to students and administrative tasks in support of district activities. An exception is virtual/Zoom-based interviewing, which has been increasingly accepted as a help in moving forward with consideration of candidates out of the immediate area, beyond simply avoiding in-person contact during the pandemic.

Employers might see long-term potential in being able to hire staff from anywhere, engaged via telework, and thus increase their organizations' pool of talent beyond the office's immediate physical vicinity. This is a shift that required employers to move beyond suspicion and distrust of the telework construct, which assumed that productivity would suffer if employees worked from home. The experience of COVID has shown the opposite in many instances - that employees work hard, and complete tasks, from home, and also appreciate the enhanced work-life balance as a benefit. This potentially results in an improved employer-employee relationship, sense of empathy, and ownership of the work product from the perspective of the employee as participant in achieving organizational goals, rather than serving as a means to an end. HR can advocate for employee well-being. This echoes a point made by Collings, McMackin, Nyberg, and Wright, who suggested that "COVID-19 highlights the need to recalibrate the discussion on the tactical versus strategic role of strategic HRM" [56]

\subsection{Vulnerability}

Respondents noted a range of concerns and problems that occurred in the COVID-19 response. Many of the problems, initially at least, seemed to stem from a lack of clear and timely direction. Some were prone to denial in the face of the threat-for example, one respondent described an organization that used a food thermometer to check employee temperatures, even though there should have been some recognition that the readings would be inaccurate. The result of such an approach was, of course, that no one had a fever, so all had to report to work - a dangerous prospect, especially at the height of the pandemic. This could point to the impact of emotional contagion in COVID-19 response [26].

The slow decision-making at the outside interfered with organizational responses, including for the HR function. One official commented that "it definitely was a very slow start. And we weren't really geared up for it. So being reactive to it ... definitely had a negative impact ... for a couple of months." Others mentioned that response to the pandemic remained poor, lacking awareness: "We're still struggling with you know, employees, their illnesses [at the time of the interviews]. COVID is still rampant throughout. So we do have some employees that have been working from home on a regular basis for fear of returning to work, if we're able to support that we do and we try for a permanent solution. We really have not devised the plan yet." Statements that agencies had done a good job with the response might be considered overconfident, in light of the delays and failures that had been experienced, the challenging nature of the pandemic in practically every respect, and a need (stated in some instances) to acknowledge uncertainty, rather than willfully charging ahead.

In some instances, problems that existed before the pandemic became more obvious as vulnerabilities during the response. An example of this is inaccuracy in job descriptions, or where the job description did not match the work of the job in practice. There can be a tendency to lump similar jobs under the same classification, but in reality, the jobs are quite different. The differences between the jobs in practice become more apparent in 
challenging contexts, and it can become very clear that the jobs are quite different and must be responded to uniquely given the context (some positions, for example, cannot work remotely, while others have activity that is amenable to telework). Changes to compensation/classification systems can be slow; in an emergency environment, the organization may not be able to respond quickly to vulnerabilities. Unfortunately, seeing where the vulnerabilities exist requires a good deal of imagination, to identify where problems could occur given certain stressors.

Processes and policies essential to performing work were sometimes not in place; learning often occurred via making mistakes. Connecting this point with the literature, with sensemaking as an enacted process, learning cannot exist for its own sake in the management of a crisis-there needs to be a connection with the creation of resilient practices, so that the organization can respond more effectively in future [57]. Shifting requirements, including CDC directives, were mentioned as challenges.

Speaking to resilience and returning to normal, several respondents made a point to define changes like telework and other adjustments as temporary. The pandemic made the move to telework necessary. There was even some admission that the telework system worked well-beyond the expectations of managers—but the goal was to go back to how things were done before for COVID, as much as possible. There were points made about initial suspicion of working from home, which gradually gave way as the potential for productivity in telework became more apparent. "It was realized quickly that some employees that were working from home were not meeting the requirements and causing conflict. Their productivity was low, and those office workers were asked to return to the office to work." However, the supporting comments seem to indicate that a lack of productivity was more an exception than the rule, especially for professionals committed to the agency/organization mission.

\subsection{Management and Leadership Considerations}

Respondents emphasized the importance of management communication in the response. Navigating the changed work environment, and addressing needs such as virtual training, were consistent comments. Negative comments centered on a lack of leadership and foresight in the response.

Some of the variation associated with COVID-19 response in the interviews in this study was associated with the type of organization. Some organizations, notably correctional facilities, cannot provide for remote work or have their provision of services virtualized, so challenges in protecting staff and clients are innate. However, these challenges are exacerbated through bad choices being made, willful ignorance on the part of leaders and decision-makers, and expressions of overconfidence in the face of uncertainty. In this respect, simple vulnerabilities are made points of critical weakness. This resulted in impacts to individuals and ultimately the organization that were far worse than if uncertainty was admitted and appropriate precautions were taken earlier, even if this may have meant undesirable admissions for political considerations or incurring additional costs. Poor leadership sets a tone that results in high absenteeism, abuse of sick leave, and poor morale, all of which negatively impact the organization and service of its mission. COVID-19 response has been an exceedingly costly proposition, but it is hubris to think that there was a cheap way out of responding to it. Such approaches turn a costly inconvenience into a personal and organizational disaster.

Sociodemographic information was not collected on interview respondents-this may be seen as a limitation of the study. However, some respondents had concern about their responses being tracked to them personally and it was decided that only essential information - the responses to the questions - would be collected, beyond the consent form. Given that student researchers were involved, the approach was simplified, to assure a minimum of practical concerns with the interviews, but also that potential respondents would want to participate and not be unduly burdened. 


\section{Conclusions}

There are significant implications to this research. It is clear, as the literature on resilience and vulnerability has shown, that organizational problems and shortfalls before a crisis persist into event response, and perhaps even worsen. The time to address vulnerability is before an event occurs. Barring adequate preparation, organizations rely on staff members' problem solving and sensemaking skills. It is quite possible that the public sector has entered a new era of awareness of risk and threats, and a need to have capacity to respond and provide for continuity of operations. While the interviews conducted for this study point to a strongly resilient response in some cases-including sensemaking activity and readily discerned examples of adaptive capacity —other interviews indicated serious concerns about response, which indicate vulnerability pre-pandemic, and missed opportunities in response and recovery. More could have been done to prepare for risks-not just COVID-19, but for future organizational challenges that stretch the ability of organizations to solve problems, to the point of threatening the existence of organizations themselves, and even the lives of staff members.

While this research is exploratory in nature, the findings are worth additional consideration. It is less reasonable to conclude that organizations have been caught entirely unaware, especially in an area that has had to address natural disaster response and recovery in recent years. What this shows is an inability in some cases to generalize response tactics, to suit different threats and still keep organizations ready to serve important public purposes. When organizations responded more successfully, with clear leadership and direction, they had the ability to engage in sensemaking, adapt to changing circumstances, and 'figure it out.' Future research might consider this and other aspects of the response, not only in addressing the potential for future pandemics, but to generalize approaches to enhance resilience, reduce levels of societal vulnerability, and improve management/leadership responses to future threats.

Funding: This research received no external funding.

Institutional Review Board Statement: The study was conducted according to the guidelines of the Declaration of Helsinki, and approved by the Institutional Review Board of University of West Florida (IRB No. 2020-055, 14 December 2020).

Informed Consent Statement: Informed consent was obtained from all subjects involved in the study.

Data Availability Statement: The data presented in this study are available on request from the corresponding author.

Acknowledgments: Special thanks to University of West Florida graduate students Terri Adams, Barry Anderson, Sabrina Baldwin, Angela Carden, Whitney Duffy, Tracy Goodbred, Alycia Grieco, Rachel Henriques, Bianca Jimmerson, Jonathan Johnson, Jared Lowe, Novlette Sang, Paul Pagano, Allison Welliver, Logan Wilde, and other members of the UWF Public Sector Human Resources Management course, Spring, 2021, for their part in conducting interviews for this project. Students were offered an opportunity to be acknowledged in the resulting manuscript for their role in interviewing, and also given the opportunity, outside the course, to participate in analysis of the resulting data and writing the manuscript. While no students expressed an interest in writing for this particular manuscript, some wished to be acknowledged for conducting interviews, as noted above.

Conflicts of Interest: The author declares no conflict of interest.

\section{References}

1. Dalton, M.; Handwerker, E.W.; Loewenstein, M.A. An Update on Employment Changes by Employer Size during the COVID-19 Pandemic: A Look at the Current Employment Statistics Survey Microdata; Working Paper WP-532; U.S. Bureau of Labor Statistics, Office of Employment and Unemployment Statistics: Washington, DC, USA, 2020.

2. Tagarev, T.; Ratchev, V. A Taxonomy of Crisis Management Functions. Sustainability 2020, 12, 5147. [CrossRef]

3. Mileti, D.S. Disasters by Design: A Reassessment of Natural Hazards in the United States; Joseph Henry Press: Washington, DC, USA, 1999.

4. Paton, D.; Smith, L.; Violanti, J. Disaster response: Risk, vulnerability and resilience. Disaster Prev. Manag. 2000, 9, 173-180. [CrossRef] 
5. Cutter, S.L. Social Vulnerability to Environmental Hazards. Soc. Sci. Q. 2003, 84, 242-261. [CrossRef]

6. Cutter, S.L.; Ash, K.D.; Emrich, C.T. The Geographies of Disaster Resilience. Glob. Environ. Chang. 2014, 29, 65-77. [CrossRef]

7. Southwick, S.M.; Bonanno, G.A.; Masten, A.S.; Panter-Brick, C.; Yehuda, R. Resilience Definitions, Theory, and Challenges: Interdisciplinary Perspectives. Eur. J. Psychotraumatol. 2014, 5, 25338. [CrossRef] [PubMed]

8. Atkinson, C.L. Toward Resilient Communities: Examining the Impacts of Local Governments in Disasters; Routledge: New York, NY, USA, 2014

9. Cutter, S.L. The Landscape of Disaster Resilience Indicators in the United States. Nat. Hazards 2015, 80, 741-758. [CrossRef]

10. Kuziemski, M.; Misuraca, G. AI Governance in the Public Sector: Three Tales from the Frontiers of Automated Decision-Making in Democratic Settings. Telecommun. Policy 2020, 44, 1-13. [CrossRef]

11. Rivera, F.I.; Kupucu, N. Disaster Vulnerability, Hazards and Resilience: Perspectives from Florida; Springer: Cham, Switzerland, 2015.

12. Holling, C.S. Resilience and Stability of Ecological Systems. Annu. Rev. Ecol. Syst. 1973, 4, 123. [CrossRef]

13. Adger, W.N. Vulnerability. Glob. Environ. Chang. 2006, 16, 268-281. [CrossRef]

14. Weick, K.E. Enacted Sensemaking in Crisis Situations. J. Manag. Stud. 1988, 25, 305-317. [CrossRef]

15. Matias, T.; Dominski, F.H.; Marks, D.F. Human Needs in Covid-19 Isolation. J. Health Psychol. 2020, 25, 871-882. [CrossRef]

16. Williams, A.; Whiteman, G.; Kennedy, S. Cross-Scale Systemic Resilience: Implications for Organization Studies. Bus. Soc. 2021, 60, 95-124. [CrossRef]

17. Carnevale, J.B.; Hatak, I. Employee adjustment and well-being in the era of COVID-19: Implications for human resource management. J. Bus. Res. 2020, 116, 183-187. [CrossRef] [PubMed]

18. United Nations. A More Secure World: Our Shared Responsibility: Report of the Secretary-General's High-Level Panel on Threats, Challenges and Change; United Nations: New York, NY, USA, 2004.

19. Ursano, R.J.; Fullerton, C.S.; McCaughey, B.G. Disaster and trauma. Harv. Ment. Health Lett. 2002, 18, 16.

20. IPCC Working Group II. Climate Change 2001: Impacts, Adaptation and Vulnerability; Cambridge University Press: Cambridge, UK, 2001.

21. Sparrow, P. To Use Competencies or Not to Use Competencies? That Is the Question. In Individual Differences and Development in Organisations; Pearn, M., Ed.; Wiley: West Sussex, UK, 2002; pp. 107-130.

22. Pelling, M. The Vulnerability of Cities: Natural Disasters and Social Resilience; Earthscan: London, UK, 2003.

23. Weick, K.E. The Collapse of Sensemaking in Organizations: The Mann Gulch Disaster. Adm. Sci. Q. 1993, 38, 628-652. [CrossRef]

24. Stephens, K.K.; Jahn, J.L.S.; Fox, S.; Charoensap-Kelly, P.; Mitra, R.; Sutton, J.; Waters, E.D.; Xie, B.; Meisenbach, R.J. Collective Sensemaking around COVID-19: Experiences, Concerns, and Agendas for Our Rapidly Changing Organizational Lives. Manag. Commun. Q. 2020, 34, 426-457. [CrossRef]

25. Harries, T.; McEwen, L.; Wragg, A. Why It Takes an "ontological Shock" to Prompt Increases in Small Firm Resilience: Sensemaking, Emotions and Flood Risk. Int. Small Bus. J. Res. Entrep. 2018, 36, 712-733. [CrossRef]

26. Belli, S.; Alsono, C.V. COVID-19 pandemic and emotional contagion. Digithum 2021, 27, 19. [CrossRef]

27. McLagan, P.; Suhadolnik, D. Models for Hrd Practice: The Research Report; ASTD: Alexandria, VA, USA, 1989.

28. Gibson, D. How to Protect Your Workforce, Operations and Values during COVID-19. 2020. Available online: https: //www.internationaltaxreview.com/article/b1m94dx49c07m3/how-to-protect-your-workforce-operations-and-valuesduring-covid19 (accessed on 20 June 2020).

29. Gomez, S.M.; Mendoza, O.E.O.; Ramirez, J.; Olivas-Lujan, M.R. Stress and Myths Related to the COVID-19 Pandemic's Effects on Remote Work. Manag. Res. J. Iberoam. Acad. Manag. 2020, 18, 401-420.

30. Piwowar-Sulej, K. Human Resource Management in the Context of Industry 4.0. Organ. Manag. Sci. Q. 2020, 1, 103-113. [CrossRef]

31. Wade, B.; Piccinini, T. Teaching Scenario Planning in Sustainability Courses; The Creative Play Method. J. Manag. Educ. 2020, 44, 699-725. [CrossRef]

32. Fu, L.; Wang, X.; Wang, D.; Griffin, M.A.; Li, P. Human and Organizational Factors within the Public Sectors for the Prevention and Control of Epidemic. Saf. Sci. 2020, 131, 104929. [CrossRef]

33. Jones, K. HR and the New Not-so-Normal. Workforce Solut. Rev. 2020, 11, 10-14.

34. Akingbola, K. COVID-19: The Prospects for Nonprofit Human Resource Management. Can. J. Nonprofit Soc. Econ. Res. 2020, 11, 16-20. [CrossRef]

35. Zimlich, R. COVID-19 Staff Reductions: How to Prevent Legal Fallout. Med. Econ. 2020, 97, 12.

36. Palumbo, R. Let Me Go to the Office! An Investigation into the Side Effects of Working from Home on Work-Life Balance. Int. J. Public Sect. Manag. 2020, 33, 771-790. [CrossRef]

37. Belzunegui-Eraso, A.; Erro-Garcés, A. Teleworking in the Context of the COVID-19 Crisis. Sustainability 2020, 12, 3662. [CrossRef]

38. Raisiene, A.G.; Rapuano, V.; Varkuleviciute, K.; Stachova, K. Working from Home-Who Is Happy? A Survey of Lithuania's Employees during the COVID-19 Quarantine Period. Sustainability 2020, 12, 5332.

39. Amis, J.M.; Janz, B.D. Leading Change in Response to COVID -19. J. Appl. Behav. Sci. 2020, 56, 272-278. [CrossRef]

40. Williamson, S.; Colley, L.; Hanna-Osborne, S. Will Working from Home Become the "new Normal" in the Public Sector? Aust. J. Public Adm. 2020, 79, 601-607. [CrossRef]

41. Alan, H. COVID-19 Pandemic and Digitalization of Service Organizations: A Trademark Approach. Turk. Stud. 2020, 15, 31-47.

42. Sawalha, I.H. A Contemporary Perspective on the Disaster Management Cycle. Foresight 2020, 22, 469-482. [CrossRef] 
43. Plantinga, H.; Voordijk, H.; Doree, A. Clarifying Strategic Alignment in the Public Procurement Process. Int. J. Public Sect. Manag. 2020, 33, 791-807. [CrossRef]

44. Ito, N.C.; Pongeluppe, L.S. The COVID-19 Outbreak and the Municipal Administration Responses: Resource Munificence, Social Vulnerability, and the Effectiveness of Public Actions. Braz. J. Public Adm. 2020, 54, 782-838. [CrossRef]

45. Vnoučková, L. Impact of COVID-19 on human resource management. Rev. Latinoam. Investig. Soc. 2020, 3, 18-21.

46. Medel, K.; Kousar, R.; Masood, T. A Collaboration-Resilience Framework for Disaster Management Supply Networks: A Case Study of the Philippines. J. Humanit. Logist. Supply Chain Manag. 2020, 10, 509-553. [CrossRef]

47. Mellish, T.I.; Luzmore, N.J.; Shahbaz, A.A. Why Were the UK and USA Unprepared for the COVID-19 Pandemic? The Systemic Weaknesses of Neoliberalism: A Comparison between the UK, USA, Germany, and South Korea. J. Glob. Faultlines 2020, 7, 9-45. [CrossRef]

48. Amankwah-Amoah, J.; Khan, Z.; Wood, G. COVID-19 and Business Failures: The Paradoxes of Experience, Scale, and Scope for Theory and Practice. Eur. Manag. J. 2020, 39, 179-184. [CrossRef]

49. Narbona, J.; Pujol, J.; Gregory, A. The Fragile Tenets of Trust. Church Commun. Cult. 2020, 5, 293-297. [CrossRef]

50. Bower, J.L. Effective public management. Harv. Bus. Rev. 1977, 55, 131-140.

51. Miles, M.B.; Huberman, A.M.; Saldaña, J. Qualitative Data Analysis: A Methods Sourcebook, 4th ed.; Sage Publications: Thousand Oaks, CA, USA, 2020.

52. Saldaña, J. The Coding Manual for Qualitative Researchers, 3rd ed.; Sage Publications: London, UK, 2016.

53. Erickson, R.A. Why Involve Students in Research? Innovations in Undergraduate Research and Honors Education: Proceedings of the Second Schreyer National Conference 2001. Available online: https://digitalcommons.unl.edu/nchcschreyer2/10/ (accessed on 11 January 2022).

54. Kuckartz, U. Qualitative Text Analysis: A Guide to Methods, Practice E Using Software; Sage Publications: London, UK, 2014.

55. Yin, R.K. Qualitative Research from Start to Finish, 2nd ed.; Guilford: New York, NY, USA, 2016.

56. Collings, D.G.; McMackin, J.; Nyberg, A.J.; Wright, P.M. Strategic Human Resource Management and COVID-19: Emerging Challenges and Research Opportunities. J. Manag. Stud. 2021, 58, 1378-1382. [CrossRef]

57. Elliott, D.; Macpherson, A. Policy and Practice: Recursive Learning from Crisis. Group Organ. Manag. 2010, 35, 572-605. [CrossRef] 